\title{
Influence of oxygen content and structural defects on low-temperature mechanical properties of high-temperature superconducting single crystals and ceramics
}

\author{
S. V. Lubenets, V. D. Natsik, L. S. Fomenko, H. -J. Kaufmann, V. S. \\ Bobrov, and A. N. Izotov* \\ B. Verkin Institute for Low Temperature Physics and Engineering of National Academy of Sciences of Ukraine, \\ 47 Lenin Ave., Kharkov, 310164, Ukraine \\ E-mail: lubenets@ilt.kharkov.ua \\ * Institute of Solid State Physics, Russian Academy of Sciences, Chernogolovka, Russia
}

Submitted January 30, 1997

\begin{abstract}
The data for the microhardness and fracture toughness of $\mathrm{Y}-\mathrm{Ba}-\mathrm{Cu}-\mathrm{O}$ and $\mathrm{Bi}$-based single crystals and ceramics in the temperature range $77-293 \mathrm{~K}$ are presented and analysed. Our study reveals that the microhardness of high temperature superconductors is very sensitive to the oxygen stoichiometry, the phase composition, the temperature, and to the microstructural defects such as impurities, intergranular boundaries, and voids. Attention is drawn to the anisotropy of the micromechanical properties and to the features of the fracture in the vicinity of the indentation. The data available on the plasticity of $\mathrm{Y}-\mathrm{Ba}-\mathrm{Cu}-\mathrm{O}$ and $\mathrm{Bi}-\mathrm{Sr}-\mathrm{Ca}-\mathrm{Cu}-\mathrm{O}$ from micro- and macrotests are compared.
\end{abstract}

PACS: 74.25.L, 81.70.D

\section{Introduction}

Practical applications of $\mathrm{Y}-\mathrm{Ba}-\mathrm{Cu}-\mathrm{O}$ and $\mathrm{Bi}-\mathrm{Sr}-$ $\mathrm{Ca}-\mathrm{Cu}-\mathrm{O}$ superconducting compounds are often limited by their poor mechanical performance, i.e., extremely low ductility and elevated brittleness, especially at low and moderate temperatures. Plasticity and strength of high-temperature superconductors (HTSCs) are adversely affected by numerous defects: voids, surface and bulk microcracks, grain and twin boundaries, phase inhomogeneities, impurities, oxygen nonstoichiometry which result from the synthesis process at high temperature and from subsequent cooling to room temperature and mechanical treatment or loading.

A study of the mechanical properties of such complicated objects, whether they are ceramics (polycrystals) or single crystals, does not appear to be a simple task. Nevertheless, several procedures have been devised for this purposes. It is possible to suppress the intrinsic brittleness of superconducting oxides and reveal clear plastic flow with dislocation generation by deforming at elevated temperatures
[1-5], at room temperature with the application of hydrostatic pressure [6] or by using shock-loading techniques [7]. However, most investigations have been made with the indentation techniques which can be used successfully over a wide range of temperatures [8-12].

The purpose of the present paper is to report new results and consider briefly some previous measurements of microhardness and fracture toughness of single crystals and ceramics of $\mathrm{Y}-\mathrm{Ba}-\mathrm{Cu}-\mathrm{O}$ and $\mathrm{Bi}-\mathrm{Sr}-\mathrm{Ca}-\mathrm{Cu}-\mathrm{O}$ compounds in the temperature range 77-293 K. The behavior of the microhardness near the $N-S$ phase transition temperature $T_{c}$ and the mechanism of microplasticity of HTSCs are of interest to us. We will discuss the dependence of $\mathrm{mi}-$ cromechanical properties on temperature, oxygen and impurity concentrations, density, and microstructural and phase inhomogeneities of ceramics, and we will estimate a difficult-to-measure property such as surface energy. Finally, we will compare the available data on the plasticity of these materials obtained from micro- and macrotests. 


\section{Experimental procedure}

The $\mathrm{Y}-\mathrm{Ba}-\mathrm{Cu}-\mathrm{O}$ and $\mathrm{Bi}-\mathrm{Sr}-\mathrm{Ca}-\mathrm{Cu}-\mathrm{O}$ compounds were prepared by high-temperature solid state reaction. Ceramic specimens were prepared first by cold pressing and then by sintering of synthesized powder. Variations in pressure $(0.2-5 \mathrm{GPa})$ and annealing temperature (1073-1233 K) permitted different densities to be attained. The Y-Ba-Cu-O test samples had a density $D$ between 2.1 and $5.85 \mathrm{~g} / \mathrm{cm}^{3}$ (0.33-0.92 of the x-ray density, $\left.D_{R}=6.38 \mathrm{~g} / \mathrm{cm}^{3}\right)$ and $T_{c}=85-92 \mathrm{~K}$. Single crystals were grown in alundum or platinum crucibles (below referred to as $\mathrm{Y}-\mathrm{Al}$ and $\mathrm{Y}-\mathrm{Pt}$, respectively) by a spontaneous crystallization technique. The crystals were flat with (001) faces dominating. The concentration of platinum in Y-Pt crystals and aluminum in $\mathrm{Y}-\mathrm{Al}$ crystals was found to be $0.01 \mathrm{wt} . \% \mathrm{Pt}$ and $0.25 \mathrm{wt}$. \% Al. The investigation of the influence of the oxygen deficiency on microhardness was carried out on $\mathrm{YBa}_{2} \mathrm{Cu}_{3} \mathrm{O}_{7-\delta}$ crystals with four concentrations of oxygen: $\delta=0.1,0.3,0.4$, and 0.9 . The oxygen index in as-grown crystals was varied by further thermal treatment in oxygen or in argon. The microindentations were carried out at room temperature by using a PMT-3 standard diamond tester and at temperatures from 77 to $300 \mathrm{~K}$ they were made by using a special tester set described in Ref. 12 . Hardness $H_{V}$ and fracture toughness $K_{c}$ (the critical stress intensity factor) were calculated by using the relations $[9,13]$

$$
\begin{gathered}
H_{V}=1.854\left(P-P_{\mathrm{th}}\right) /(2 a)^{2}, \\
K_{c}=0.016\left(E / H_{V}\right)^{1 / 2}\left(P-P_{\mathrm{th}}\right) / c^{3 / 2},
\end{gathered}
$$

where $2 a$ is the impression diagonal; $P$ is the indentation load; $P_{\text {th }}$ is the threshold load which does not result in an impression or a crack; $E$ is the elastic constant (along the axes [100] and [010] $E_{11}=$ $=E_{22}=156 \mathrm{GPa}$ and along the axis [001] $E_{33}=$ $=89 \mathrm{GPa}$ for $\mathrm{Y}-\mathrm{Ba}-\mathrm{Cu}-\mathrm{O}$ at room temperature [14]). The experimental data plotted in the coordinates $(2 a)^{2}-P$ and $c^{3 / 2}-P$ are well described by the linear relations giving the load-independent values of $H_{V}$ and $K_{c}$.

\section{Results and discussion}

\subsection{Y-Ba-Cu-O system. Single crystals}

Effect of oxygen content on microhardness. The hardness of the Y-Ba-Cu-O system is highly sensitive to oxygen concentration $[12,15,16]$. The results of our measurements are shown in Fig. 1 for three temperatures. The strongest concentration depend-

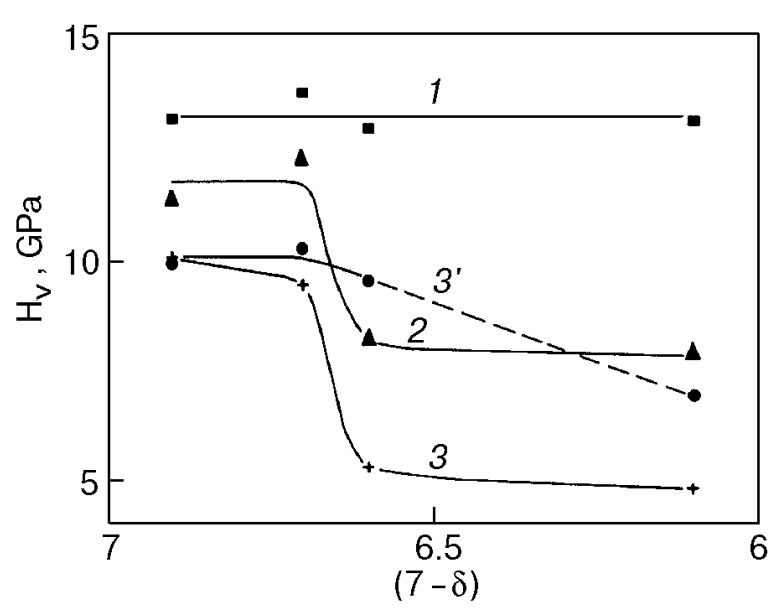

Fig. 1. Effect of oxygen concentration in $\mathrm{Y}-\mathrm{Ba}-\mathrm{Cu}-\mathrm{O}$ single crystals on microhardness at temperatures 77 (1), 200 (2), and $293 \mathrm{~K}$ ( 3 and 3'). Curves 1, 2, and 3 correspond to crystals from the series Y-Pt, and curve 3' corresponds to the Y-Al crystals.

ence $H_{V}(\delta)$ for Y-Pt crystals is observed at room temperature: the hardness changes about 1.5 times in the $\delta$ interval from 0.3 to 0.4 , i.e., in the range of orthorhombic-1 $\rightarrow$ orthorhombic-2 phase transition, but it is not affected by orthorhombic-tetragonal phase transition $(\delta \simeq 0.5)$. Thus, the sharp variation of $H_{V}$ can apparently be associated with the variation in the properties of the lattice within the orthorhombic symmetry due to one-dimensional ordering of oxygen vacancies. The aluminum impurity in Y-Al crystals weakens the softening effect and extends the range of microhardness-oxygen concentration dependence toward higher values of $\delta$.

The strong effect of oxygen stoichiometry on the plasticity of $\mathrm{Y}-\mathrm{Ba}-\mathrm{Cu}-\mathrm{O}$ speaks in favor of shear in the $\mathrm{BaO} / \mathrm{CuO}$ plane, since the main variations upon changing the oxygen index, occur just in the $\mathrm{CuO}$ plane.

The available data $[17,18]$ show that the elastic moduli corresponding mainly to shear modes increase monotonically with oxygen concentration. The moduli corresponding to dilatation modes increase up to the values $\sim 6.7$ of the oxygen index, after which they begin to decrease. Consequently, the considered behavior of $H_{V}(\delta)$ is due not to the variation of the elastic properties of crystals but to the effect of oxygen concentration and oxygen ordering on the core structure and mobility of dislocations.

The microhardness and fracture toughness of $\mathrm{Y}-\mathrm{Ba}-\mathrm{Cu}-\mathrm{O}$ and some rare-earth cuprates $\mathrm{Re}-\mathrm{Ba}-\mathrm{Cu}-\mathrm{O}$ (Re: Gd, Ho, Dy, Er, Yb) single crystals studied are shown to vary over wide ranges: at room temperature $H_{V}=5-10 \mathrm{GPa}$ and $K_{c}=0.4-1 \mathrm{MPa} \mathrm{m}^{1 / 2}$ $[8,9,12,19]$. This considerable spread of the meas- 
ured values may be attributed to the variations in oxygen concentration which was not controlled.

Mechanical anisotropy of $\mathrm{Y}-\mathrm{Ba}-\mathrm{Cu}-\mathrm{O}$ crystals. The hardness of $\mathrm{Y}-\mathrm{Ba}-\mathrm{Cu}-\mathrm{O}$ crystals was found to be isotropic within an experimental error. However, the special measurements made on relatively large crystals with well-developed (100) and (001) faces have demonstrated that the hardness ratio of (100) to (001) surfaces is 1.2 for the orthorhombic phase and 1.8 for the tetragonal phase [20].

The length of cracks and the direction of their propagation are very sensitive to indentation crystallography. Cleavage of these layered structures is easier along basal planes $[9,14]$. That is the reason why the hardness of aligned $\mathrm{Y}-\mathrm{Ba}-\mathrm{Cu}-\mathrm{O}$ was found to be strongly anisotropic [21]: preferential cleavage of the basal planes results in much lower hardness for indentation on the $(100) /(010)$ plane than on the (001) plane: 3.8 and $6.7 \mathrm{GPa}$, respectively.

Notice that the mechanical anisotropy may be affected by the presence of twin boundaries. Hardness was found to be insensitive to a twin structure, which arose during the tetragonal-orthorhombic phase transition; however, the fracture toughness for twinned crystals was different than that for untwinned crystals, according to Ref. 14.

Temperature dependence of microhardness. So far, only few results of an experimental study of the temperature dependence of the microhardness of $\mathrm{Y}-\mathrm{Ba}-\mathrm{Cu}-\mathrm{O}$ single crystals have been reported. However, they cover a wide temperature range from the boiling point of liquid nitrogen to almost $1200 \mathrm{~K}$ and concern both phases of the $\mathrm{Y}-\mathrm{Ba}-\mathrm{Cu}-\mathrm{O}$ compound, i.e., tetragonal and orthorhombic phases. We have summarized the basic data in Fig. 2.

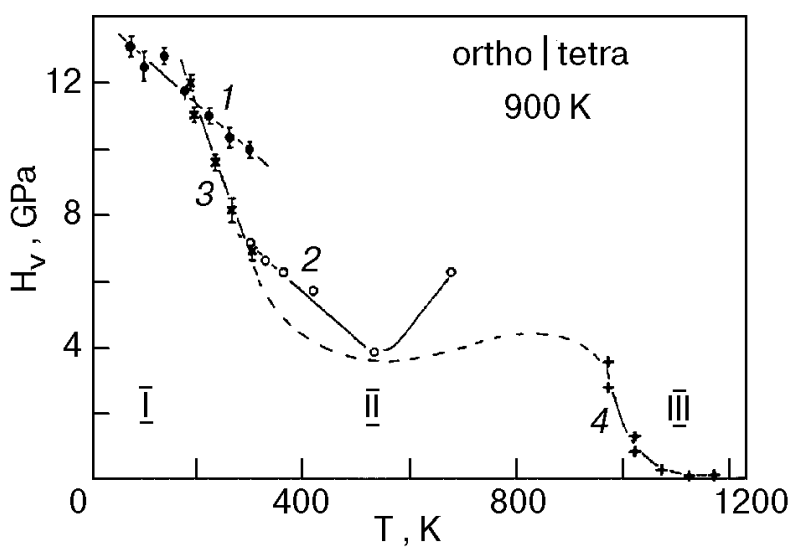

Fig. 2. Microhardness of $\mathrm{Y}-\mathrm{Ba}-\mathrm{Cu}-\mathrm{O}$ single crystals as a function of temperature: the orthorhombic phase, $\delta=0.1$ (1) [12]; the orthorhombic phase, as-grown (2) (Ref. 20); the tetragonal phase, $\delta=0.9$ (3) (Ref. 12); the tetragonal phase (4) (Ref. $10)$.
Notice a linear increase in the hardness of the orthorhombic phase (Fig. 2, curve 1) with decreasing temperature, without any anomalies near $T_{c} \simeq 93 \mathrm{~K} \mathrm{[12].} \mathrm{The} \mathrm{data} \mathrm{obtained} \mathrm{for} \mathrm{softer} \mathrm{crys-}$ tals and at a higher temperature [22] (Fig. 2, curve 2) show a similar temperature dependence. The increase of $H_{V}$ at $T>550 \mathrm{~K}$ can be attributed to the changes in oxygen stoichiometry. Samples with the tetragonal structure exhibit lower hardness at room temperature, which increase rapidly, with decreasing temperature, and a sharp transition from ductile behavior to brittle fracture at about $200 \mathrm{~K}$ Ref. 12 (Fig. 2, curve 3). Analogous $H_{V}$ and their low-temperature dependences of normal brittle semiconductors (e.g., $\mathrm{Si}, \mathrm{Ge}$ ) and $\mathrm{Y}-\mathrm{Ba}-\mathrm{Cu}-\mathrm{O}$ single crystals can indicate that in region I the similar thermally activated dislocation mechanisms control plastic deformation produced by indentation [12] It may be suggested that strong covalent bonds (in the first case) and ionic bonds (in the second case) create high Peierls barriers, which constrain the dislocation mobility in these crystals.

The high-temperature deformation processes in the tetragonal phase (region III, Fig. 2, curve 4; Ref. 10) are obviously diffusion assisted. In the intermediate region II the mixed dislocation-diffusion mechanisms are expected to control plastic flow (see, for example, Refs. 5 and 23 and the bibliography cited there).

Fracture toughness and surface energy. Measurements of the temperature dependence of the fracture toughness have been carried out with two series of $\mathrm{Y}-\mathrm{Ba}-\mathrm{Cu}-\mathrm{O}$ single crystals: $\mathrm{Y}-\mathrm{Al}$ and $\mathrm{Y}-\mathrm{Pt}$ [24]. They are characterized by the same oxygen index $\delta \simeq 0.3-0.4$ and the same critical temperature $T_{c} \simeq 60 \mathrm{~K}$. For Y-Pt crystals, a decrease of $H_{V}$ and $K_{c}$ with increasing temperature arises from thermally activated dislocation glide. This provides evidence for a quasi-brittle type of fracture. In contrast, a weak rise of $K_{c}$ of Y-Al crystals from $3.4 \mathrm{MPa} \cdot \mathrm{m}^{1 / 2}$ (at $77 \mathrm{~K}$ ) to $3.5 \mathrm{MPa} \cdot \mathrm{m}^{1 / 2}$ (at $292 \mathrm{~K}$ ) (and a weak drop of $H_{V}$ from $9.3 \mathrm{GPa}$ (at $77 \mathrm{~K}$ ) to $8.5 \mathrm{GPa}$ (at $292 \mathrm{~K}$ ) with increasing temperature may point to an ideally brittle mode of fracture, without allowance for the glide dislocations or with their slight participation. In this situation, the calculated values of $K_{c}$ are determined essentially by the material constants. Using the Griffith-Orovan relation $K^{2}=2 \gamma E /\left(1-v^{2}\right)$, where $v$ is the Poisson ratio, we could estimate the surface energy $\gamma$ of two surfaces $(100) /(010)$ and (001). The (001) face indentation gives an average $K_{c}$ of about $0.35 \mathrm{MPa} \cdot \mathrm{m}^{1 / 2}$ and hence $\gamma_{100 / 010} \simeq$ $\simeq 360 \mathrm{erg} / \mathrm{cm}^{2}$. An indentation of $(100) /(010)$ 
face showed a large anisotropy in crack length for crack directions perpendicular to and parallel to the basal plane (cf. Refs. 14-16, and 19): $K_{c} \simeq$ $\simeq 0.7 \mathrm{MPa} \cdot \mathrm{m}^{1 / 2}$ and $\gamma_{100 / 010} \simeq 1400 \mathrm{erg} / \mathrm{cm}^{2}$ in the first case and $K_{c} \simeq 0.2 \mathrm{MPa} \cdot \mathrm{m}^{1 / 2}$ and $\gamma_{001} \simeq$ $\simeq 160 \mathrm{erg} / \mathrm{cm}^{2}$ in the second case.

\section{Ceramics}

Indentation technique is very useful in estimating the density and homogeneity of samples because of the possibility of accurately locating the impressions on the surface and through the sensitivity of microhardness to the presence of structural and other defects. This is particularly evident in measurements on ceramics.

The influence of microstructure inhomogeneities on the hardness of $\mathrm{Y}-\mathrm{Ba}-\mathrm{Cu}-\mathrm{O}$ ceramics is reflected very distinctly in histograms and in average values of hardness [19]. The hardness in the vicinity of grain boundaries is smaller and its dispersion is higher than they both measured within grains. The role of intergrain material in the formation of the ductility of ceramics can be demonstrated best of all by the example of fine-grain ceramics with the grain size $d \simeq 5 \mu \mathrm{m}$. Its average hardness was found to be smaller by a factor of 3 as compared with that of ceramics of about the same density with $d \simeq$ $\simeq 40 \mu \mathrm{m}$, which indicates the determining influence of grain boundaries on the impression formation.

The temperature dependences of the microhardness of ceramics with an average grain size $d \simeq 5 \mu \mathrm{m}$ and different densities $D / D_{R}=0.73,0.91$, and 0.98 are plotted in Fig. 3 [25]. Figures 3, $a$ and 3,b show the data of $H_{V}$ measurements at an indentor load $P_{1}=0.15 \mathrm{~N}$ and $P_{2}=2 \mathrm{~N}$, respectively. At the $P_{1}$ load an impression area was very nearly equal to the grain area, whereas at the $P_{2}$ load it far exceeded the grain area. The measured values of $H_{V}$ at $P_{2}$ characterize the hardness of given ceramics on average, as a whole, and then they are less than $H_{V}$ values obtained at indentation with smaller load $P_{1}$. The smaller the load on the indentor, the closer are the measured values to the hardness of the grains. From Fig. 3 we see that the hardness is near-linear with temperature without any detectable features in the range from 77 to $293 \mathrm{~K}$ for all samples examined, but, what is more important in this context, it depends strongly on density.

Recently [19] we studied the dependence of the hardness on the density of $\mathrm{Y}-\mathrm{Ba}-\mathrm{Cu}-\mathrm{O}$ ceramics in the interval of $D / D_{R}=0.33-0.92$ at room temperature and deduced from the experiments that the hardness increases exponentially with increasing density (see also Ref. 26), as is usually observed for many structural ceramics:

$$
H_{V}=H_{V 0} \exp \left[-n\left(1-D / D_{R}\right)\right] .
$$

This equation adequately describes the data in Fig. 3 at all temperatures (the plots for two fixed temperatures, 77 and $293 \mathrm{~K}$, are presented in the insets in Figs. $3, a$, and $3, b)$. The $H_{V 0}$ value de-
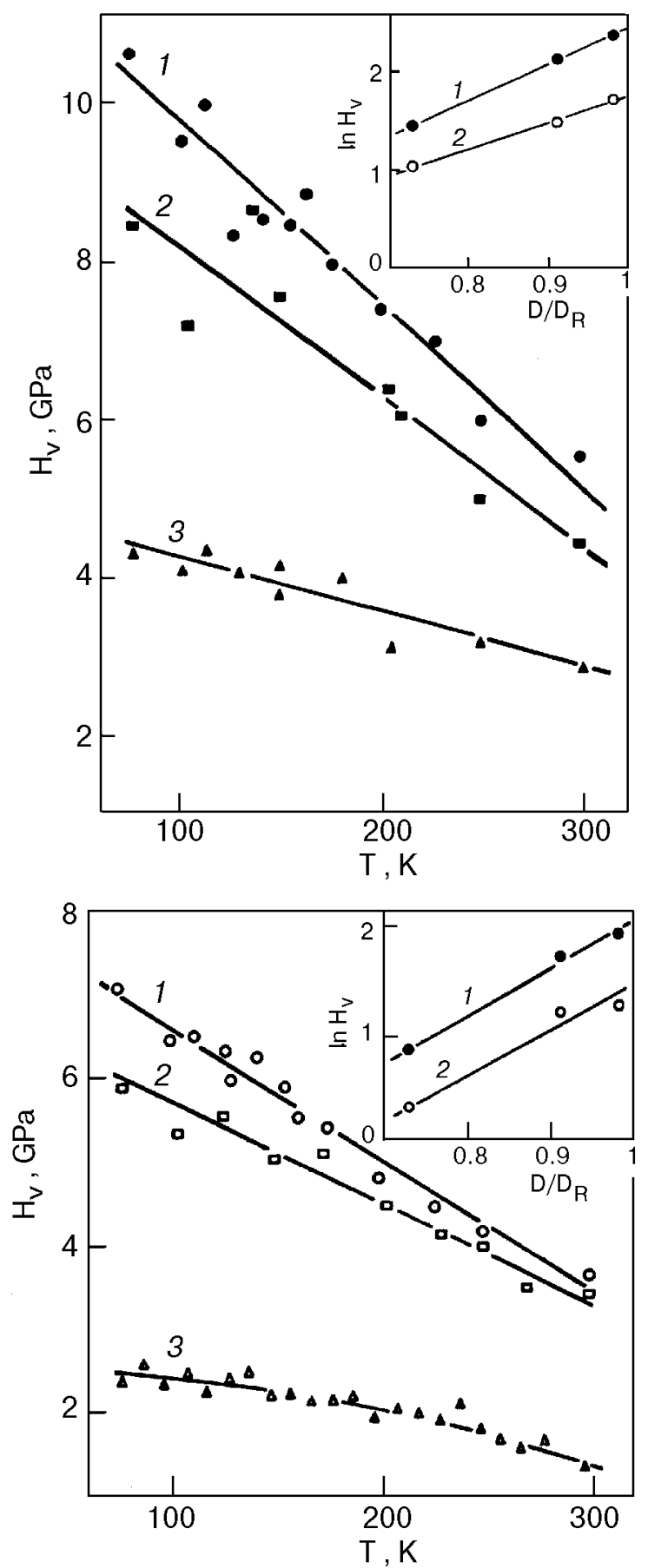

Fig. 3. Microhardness of $\mathrm{Y}-\mathrm{Ba}-\mathrm{Cu}-\mathrm{O}$ ceramics as a function of temperature, at the loads on the indentor $P_{1}=0.15 \mathrm{~N}(a)$ and $P_{2}=2 \mathrm{~N}(b)$. Relative density $D / D_{R}=0.98$ (1), 0.91 (2), and 0.73 (3). The insets show $D / D_{R}$ dependences of $\ln H_{V}$ at two temperatures $77(1)$ and $293 \mathrm{~K}(2)$. 
creases with increasing temperature from 8.1 to 4.6 GPa at $P_{2}=2 \mathrm{~N}$ and from 11.6 to $5.7 \mathrm{GPa}$ at $P_{1}=0.15 \mathrm{~N}$. The factor $n$ in the exponent is equal to 4.6 at a load of $2 \mathrm{~N}$ independently of temperature. At a load of $0.15 \mathrm{~N}$ the $n$ value increases from 2.6 at $293 \mathrm{~K}$ to 3.6 at $77 \mathrm{~K}$. An increase in the value of $n$ with decreasing temperature and an increase in the load is likely due to the crack formation along the grain boundaries. These microcracks enhance the dependence of hardness on density, which in the initial ceramics is determined by the intrinsic voids.

The maximum hardnesses of grains in ceramic samples and single crystals of the same oxygen concentration are in good agreement in the whole temperature range from 77 to $293 \mathrm{~K}$.

\subsection{Bi-Sr-Ca-Cu-O system}

The Bi-containing HTSC ceramics and crystals exhibited highly nonuniform micromechanical properties [27]. The hardness of single crystals at room temperature was found to have three typical values: $0.5,1.1$, and $3.1 \mathrm{GPa}$. The data observed are close to those measured individually on two types of ceramic crystallites with different optical reflective capacities: $0.43 \mathrm{GPa}$ and $1.08 \mathrm{GPa}$ for «dark» crystallites and $3.8 \mathrm{GPa}$ for «bright» crystallites. These values are considerably lower than the microhardness of a Y-Ba-Cu-O system.

Nonuniform mechanical properties of a Bi-Sr-Ca$\mathrm{Cu}-\mathrm{O}$ system apparently are attributable to their multiphase nature. Preparation of single-phase crystals of this system is seriously hindered by different causes. As was demonstrated, nearly single phase material (2212) can be obtained only by thoroughly controlling the processing parameters: the oxygen pressure, the maximum sintering temperature, the

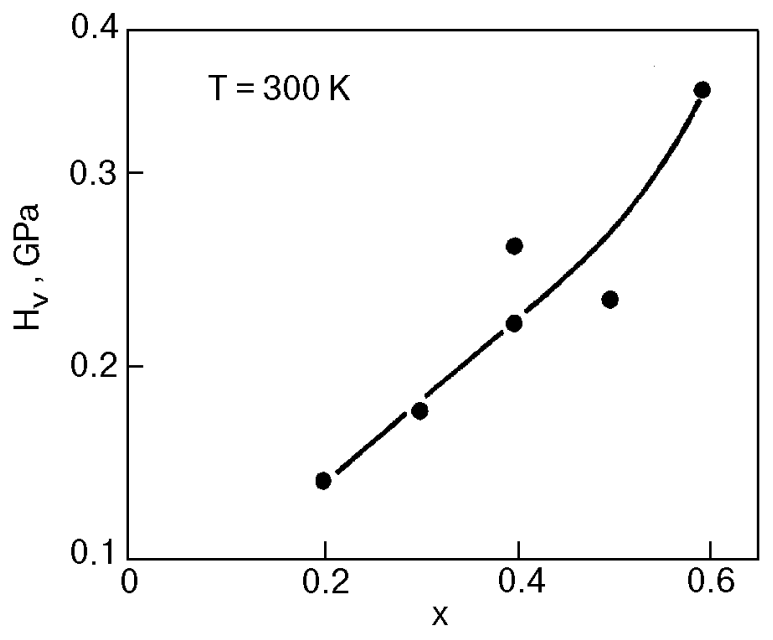

Fig. 4. Microhardness of $\mathrm{Bi}_{2-x} \mathrm{~Pb}_{x} \mathrm{Sr}_{2} \mathrm{Ca}_{2} \mathrm{Cu}_{3} \mathrm{O}_{y}$ ceramics as a function of $\mathrm{Pb}$ dopant concentration at room temperature.

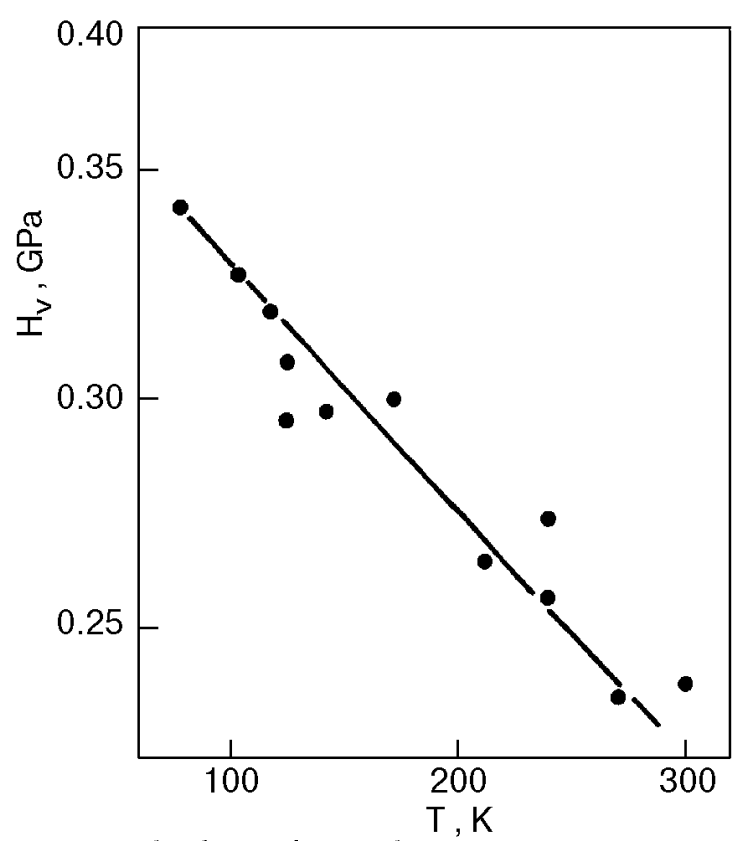

Fig. 5. Microhardness of $\mathrm{Bi}_{2-x} \mathrm{~Pb}_{x} \mathrm{Sr}_{2} \mathrm{Ca}_{2} \mathrm{Cu}_{3} \mathrm{O}_{y}$ ceramics as a function of temperature for $x=0.4$.

annealing time, and the cation stoichiometry [28]. The high quality (2223) phase samples were also prepared [29,30].

Addition of $\mathrm{Pb}$ dopant to the $\mathrm{Bi}-\mathrm{Sr}-\mathrm{Ca}-\mathrm{Cu}-\mathrm{O}$ system stabilizes the 2223 phase and therefore hardens the $\mathrm{Bi}_{2-x} \mathrm{~Pb}_{x} \mathrm{Sr}_{2} \mathrm{Ca}_{2} \mathrm{Cu}_{3} \mathrm{O}_{\mathrm{y}}$ ceramics [31]. Figure 4 shows the microhardness plotted as a function of $\mathrm{Pb}$ dopant concentration. Measurements were performed at room temperature by using six samples with different values of $x$ but approximately the same density $D / D_{R}$, between 0.6 and 0.7 . The microhardness increases almost 2.5 times with increasing $x$ from 0.2 to 0.6 . Near-linear rise of $H_{V}$ with $x$ is probably caused by solid-solution hardening. A deflection of $H_{V}(x)$ from the linear dependence at $x=0.6$ may result from $\mathrm{Ca}_{2} \mathrm{PbO}_{4}$ particle formation, which leads to additional precipitate hardening.

The microhardness of the $\mathrm{Bi}_{2-x} \mathrm{~Pb}_{x} \mathrm{Sr}_{2} \mathrm{Ca}_{2} \mathrm{Cu}_{3} \mathrm{O}_{y}$ ceramics increases with decreassing temperature and, as with the $\mathrm{Y}-\mathrm{Ba}-\mathrm{Cu}-\mathrm{O}$ system, has no anomalies in the range $T_{c}=105-110 \mathrm{~K}$. Figure 5 shows the $H_{V}$ values and their changes in the temperature interval from 77 to $293 \mathrm{~K}$ for a sample with $x=0.4$.

Microhardness measurements with the Knoop indenter carried out on the (001) face of 2223 crystals showed polar hardness anisotropy between $H_{\min }=$ $=0.9 \mathrm{GPa}$ and $H_{\max }=1.33 \mathrm{GPa}$ for azimuth $45^{\circ}$ [the short diagonal of the indenter was parallel to the (100) face] and $0^{\circ}\left(\right.$ or $\left.90^{\circ}\right)$, respectively [32]. The corresponding data for 2212 crystals [33] are $H_{\text {min }}=0.8 \mathrm{GPa}$ and $H_{\max }=2.5 \mathrm{GPa}$. Attention was drawn to a correlation between the $H_{\max }$ and 
$T_{c}$ values for HTSC materials [32,34,35]: the higher the $H_{\max }$ the lower $T_{c}$ (in particular, for the 2212 phase $T_{c}=85 \mathrm{~K}$ and for the 2223 phase $T_{c}=$ $=100-110 \mathrm{~K})$. This correlation seems to support the notion that superconductors with higher $T_{c}$ values have a more friable crystal structure.

The other feature of the Bi-Sr-Ca-Cu-O crystals is considerable lateral cracking or crushing as a result of indentation. As a result, well-developed radial cracks were rarely visible. An estimation of fracture toughness showed values as low as 0.11

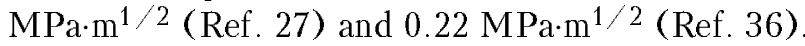
Lateral cracking causes the formation of surface relief in the form of a «roof». The residual strain of this blister is estimated to be no less than $1 \%$.

\section{Comparision of micro- and macrocharacteristics}

Some data on the plasticity of $\mathrm{Y}-\mathrm{Ba}-\mathrm{Cu}-\mathrm{O}$ and $\mathrm{Bi}-\mathrm{Sr}-\mathrm{Ca}-\mathrm{Cu}-\mathrm{O}$ compounds obtained in micro- and macrotests can be compared. In the temperature range where the material is normally brittle, the empirical ratio of microhardness to yield stress is found to be about 3 (Ref. 37). In accordance with the available data for $\mathrm{Y}-\mathrm{Ba}-\mathrm{Cu}-\mathrm{O}$ ceramics, the maximum $H_{V}=4.3 \mathrm{GPa}$ (Ref. 19) and $\sigma_{y}=$ $=1.25 \mathrm{GPa}$ (Ref. 6, ) hence $H_{V} / \sigma_{y}=3.2$. It is of interest to compare the microhardness and the strength of the single crystals. At $77 \mathrm{~K}, H_{V}=$ $=13.2 \mathrm{GPa}$ (Ref. 12), and the strength $\sigma_{T}=3.1-$ $5.4 \mathrm{GPa}$, as measured at the same temperature in a field-ion microscope $[38,39]$, therefore, $H_{V} / \sigma_{T}=$ $=4.3-2.6$. We note that the $\sigma_{T}$ values are close to the theoretical strength of a perfect crystal: $\sigma_{T} / E_{33}=1 / 16-1 / 30$.A similar value of $\sigma_{T} \cong$ $\cong 4.3 \pm 0.7 \mathrm{GPa}$ at $78 \mathrm{~K}$ was found for $\mathrm{LuBa}_{2} \mathrm{Cu}_{3} \mathrm{O}_{7-\delta}$ single crystals of diameter 74-245 nm in Ref. 40 .

There are data on hardness of $\mathrm{Bi}-\mathrm{Sr}-\mathrm{Ca}-\mathrm{Cu}-\mathrm{O}$ (2212) crystals [27, 41], and tensile strength and elastic modulus of whiskers [42] at room temperature: the maximum $H_{V}=3.1 \mathrm{GPa}$ (Ref. 27) and $H_{V}=6.2 \mathrm{GPa}$ (Ref. 41), $\sigma_{c}=0.94 \mathrm{GPa}$ and $E=$ $=92 \mathrm{GPa}$ (Ref. 42); therefore, $H_{V} / \sigma_{c}=3.3-6.6$ and $\sigma_{c} / E=1 / 100$. In this case it is clear that, first, the yield point was not reached because of the brittle fracture of whiskers and, secondly, $\sigma_{c}$ is less than $\sigma_{T}$ because of the large cross section of whiskers more than $50 \mu \mathrm{m}^{2}$.

This study was supported by the Ukraine State Committee for Science and Technology (Project 09.01.01/033-92 «Material»). The authors take the opportunity to express their gratitude to Mrs. A. I. Filatova for help in the preparation of this paper.
1. T. Yoshida, K. Kuroda, and H. Saka, Philos. Mag. A62, $573(1990)$

2. V. N. Kuznetsov, V. I. Shalaev, V. V. Sagaradze, E. V. Dusje, V. L. Arbuzov, A. E. Davletshin, V. R. Poskrebyshev, and S. M. Cheshnitskii, Sverkhprovodimost' 5, 1939 (1992).

3. J. L. Routbort, D. J. Miller, E. J. Zamirovski, and K. C. Goretta, Supercond. Sci. Technol. 6, 337 (1993).

4. M. F. Imaev, F. F. Musin, R. O. Kaibyshev, and M. R. Shagiev, Doklady RAN 338, 184 (1994).

5. K. C. Goretta, E. J. Zamirovski, J. M. Calderon-Moreno, D. J. Miller, Nan Chen, T. G. Holesinger, and J. L. Routbort, J. Mater. Res. 9, 541 (1994).

6. J. Rabier and M. F. Denanot, J. Less Comm. Met. 164165, 223 (1990).

7. M. Verwerft, D. K. Dijken, J. Tm. De Hosson, and A. C. Van Der Steen, Phys. Rev. B50, 3271 (1994).

8. R. F. Cook, T. R. Dinger, and D. R. Clarke, Appl. Phys. Lett. 51, 454 (1987).

9. V. V. Demirskii, H.-J. Kaufmann, S. V. Lubenets, V. D. Natsik, and L. S. Fomenko, Sov. Phys. Solid State 31, 1065 (1989)

10.H. Saka, J. Inagaki, T. Joshida, T. Murase, and K. Kuroda, JJAP Ser. 2, Lattice Defects in Ceram., 143 (1989).

11. V. S. Bobrov, I. I. Zwerkova, A. P. Ivanov, A. N. Izotov, A. A. Novomlinskii, R. K. Nikolaev, Yu. A. Osipyan, N. S. Sidorov, and V. Sh. Shekhtman, Fiz. Tverd. Tela 32, 826 (1990).

12. B. Ya. Farber, N. S. Sidorov, V. I. Kulakov, Yu. A. Iunin, A. N. Izotov, G. A. Emelchenko, V. S. Bobrov, L. S. Fomenko, V. D. Natsik, and S. V. Lubenets, Sverkhprovodimost' 4, 2394 (1991).

13. G. R. Anstis, P. Chanticul, R. P. Lawn, and D. B. Marshall, J. Amer. Ceram. Soc. 64, 533 (1981).

14. A. S. Raynes, S. W. Freiman, F. W. Gayle, and D. L. Kaiser, J. Appl. Phys. 70, 5254 (1991).

15. T. Graf, G. Triscone, and J. Muller, J. Less Comm. Met. 159, 349 (1990)

16. S. V. Lubenets, V. D. Natsik, L. S. Fomenko, V. S. Bobrov, and A. N. Izotov, Low Temp. Phys. 21, 247 (1995).

17. H. Ledbetter, J. Mater. Res. 7, 2905 (1992).

18. S. Lin, M. Lei, and H. Ledbetter, Mater. Lett. 16, 165 (1993)

19. V. V. Demirskii, S. V. Lubenets, V. D. Natsik, M. N. Sorin, L. S. Fomenko, and N. M. Chaykovskaya, Sverkhprovodimost' 3, 84 (1990).

20.E. Cruceanu, J. Deutz, H. Klein, W. Schmitz, and H. UlImaier, Mater. Sci. Engn. A160, L9 (1993)

21. A. Goyal, P. D. Funkenbusch, D. M. Kroeger, and S. J. Burns, J. Appl. Phys. 71, 2363 (1992).

22. V. S. Bobrov, V. K. Vlasko-Vlasov, G. A. Emelchenko, M. L. Indenbom, M. A. Lebedkin, Yu. A. Osipyan, V. A. Tatarchenko, and B. Ya. Farber, Fiz. Tverd. Tela 31, 93 (1989).

23. M. Jimenez-Melendo, A. R. De Arellano-Lopez, A. Dominguez-Rodriguez, K. C. Goretta, and J. L. Routbort., Acta Metall. Mater. 43, 2429 (1995).

24. S. V. Lubenets, V. D. Natsik, L. S. Fomenko, M. N. Sorin, N. M. Chaykovskaya, V. S. Bobrov, A. N. Izotov, and A. A. Zhokhov, Sverkhprovodimost' 6, 1406 (1993).

25. S. V. Lubenets, V. D. Natsik, L. S. Fomenko, I. A. Lyashenko, and I. T. Ostapenko, III Vsesojuzn. Sovesch. VTSP (Thezisy), Kharkov (1991), p. 76.

26. W. H. Tuan and J. M. Wu, J. Mater. Sci. 28, 1415 (1993). 
27. S. V. Lubenets, V. D. Natsik, M. N. Sorin, L. S. Fomenko, N. M. Chaykovskaya, H. -J. Kaufmann, and K. Fischer, Sverkhprovodimost' 3, 1857 (1990).

28. B. Hebb, L. J. Gauckler, H. Heinrich, and G. Kostorz, J. Electric Mater. 22, 1279 (1993).

29. H. Zhang, F. Ritter, T. Frieling, B. Kindler, and W. Assmus, J. Appl. Phys. 77, 3704 (1995).

30.I. F. Kononyuk, V. V. Washuk, L. V. Makhnach, and Yu. G. Zonov, Sverkhprovodimost' 3, 298 (1990).

31. I. F. Kononyuk, L. D. Makhnach, S. V. Lubenets, V. D. Natsik, and L. S. Fomenko, III Vsesojuzn. Sovesch. VTSP (Thezisy), Kharkov (1991), p. 75.

32. V. N. Osipov, L. I. Derkachenko, Yu. G. Nosov, V. N. Gurin, W. Jung, and R. Muller, Solid State Commun. 97, 377 (1996).

33. Tong B. Tang and S. C. Fung, Solid State Commun. 87, 325 (1993).

34. V. N. Osipov, Yu. G. Nosov, V. N. Gurin, I. N. Zimkin, N. F. Kartenko, and S. P. Nikanorov, Sov. Phys. Solid State 36, 2451 (1994).
35. T. S. Orlova, B. I. Smirnov, and V. V. Shpeizman, Sov. Phys. Solid State 32, 1838 (1990).

36. J. H. Jia and Q. P. Kong, Phys. Status Solidi A145, K51 (1994).

37. D. Tabor, The Hardness of Metals, Oxford, Clarendon Press (1951).

38. E. F. Talantsev, V. A. Ivchenko, and N. N. Syutkin, Sverkhprovodimost' 3, 2017 (1990).

39. I. M. Mikhailovskii, E. V. Sadanov, V. A. Ksenofontov, and O. A. Velikodnaya, Sverkhprovodimost' 5, 1453 (1992).

40.E. F. Talantsev, Supercond. Sci. Techn. 7, 491 (1994).

41. M. Muralidhar, Reddy K. Narasimha, and V. Hari Babu, Phys. Status Solidi (a) 126, 115 (1991).

42. I. Matsubara, J. Hashimoto, K. Atago, H. Yamashita, M. Kinoshita, and T. Kawai, J. Appl. Phys. 31, Part 2, No 1 A/B. L14 (1992). 